\title{
Na "periferia" da quadra: Educação Física, cultura e sociabilidade na escola
}

\author{
Rogério Cruz de Oliveira*, Jocimar Daolio**
}

\section{Resumo}

O objetivo do estudo é analisar a participação e a apropriação da aula de Educação Física pelos alunos que ali se encontram à margem, na "periferia" da quadra. 0 estudo, desenvolvido numa escola pública, deu-se a partir do método etnográfico, tendo como instrumento de coleta de dados a observação e a entrevista semiestruturada. A partir dessa imersão, compreendeu-se a participação e a apropriação da aula de Educação Física pelos alunos em três categorias: "pedacinho" (im)praticante, "pedacinho" ativo e "pedacinho" flutuante. Embora diferentes, os três "pedacinhos" elucidaram a existência de estereótipos, preconceitos e desigualdades de oportunidades. Dessa forma, houve, por parte dos alunos, uma apropriação limitada dos conhecimentos da Educação Física. Entretanto, mesmo inseridos num horizonte limitador de ensino-aprendizagem da Educação Física, os alunos vivenciaram sua sociabilidade na perspectiva de um tempo e um espaço de livre convivência com o outro.

\section{Palavras-chave}

Educação Física, escola, cultura, sociabilidade.
* Universidade Federal de São Paulo (Unifesp - Baixada Santista), Santos, SP, Brasil. rogerio.unifesp@gmail.com

* * Universidade Estadual de Campinas (Unicamp), Campinas, SP, Brasil. jocimar@fef.unicamp.br 


\title{
At the Court's "Periphery": Physical Education, Culture and Sociability in School
}

\begin{abstract}
The aim of this study was to analyze the participation and appropriation of the physical education class for students who are in its margins, at the "periphery" of the sports' court. The study was carried out in a public school as an ethnography, relying on observations and semi-structured interviews. The results showed that participation and appropriation of the physical education class fell into three categories: (not) practicing, active and floating. The analysis of each category has contributed to elucidate the existence of different stereotypes, prejudice and thus inequality of opportunities in the physical education class. Nevertheless, although there was, on the part of the students, limited acquisition of knowledge on Physical Education, they could develop experiences of sociability with each other free from the formal constraints usually found in classrooms.
\end{abstract}

Keywords

Physical Education, school, culture, sociability. 


\section{Introdução}

Compreender a Educação Física (EF) como componente curricular da educação básica não é algo novo. Entretanto, o entendimento dela no contexto escolar ainda está distante da legitimidade. Isso porque a imagem da EF foi consolidada ao longo da história como disciplina de menor valor, menor prestígio e menor validade (Bracht et al., 2003).

Assim, é comum, em aulas de EF, alunos sentados à beira da quadra conversando, estudando conteúdo de outros componentes curriculares ou, simplesmente, aguardando o término da aula.

$\mathrm{Na}$ intenção de categorizar todo esse "pano/plano" de fundo que envolve a EF escolar, é que propomos, neste estudo, o conceito de "periferia" da quadra. Em nosso entendimento, para além das situações descritas acima, a "periferia” da quadra é uma referência subjetiva aos tempos da aula de EF vivenciados pelos alunos que se distanciam da proposta inicial do professor.

Dessa forma, assumimos o entendimento de que a aula de EF acontece para todos, independentemente do grau de envolvimento do aluno, e os que ficam sentados ou fazendo outras coisas não estão sumariamente excluídos dela, mas, sim, vivenciam diversas possibilidades de envolvimento permitidas pela proposta da aula.

O texto aqui apresentado é originado de tese de doutorado que objetivou compreender a dinâmica cultural dos alunos que se situam à margem das aulas de Educação Física - na "periferia” da quadra -; analisar a participação e a apropriação das aulas de Educação Física por esses alunos; e investigar os fatores que permitem a existência do fenômeno da "periferia" da quadra.

Entretanto, dentro dos limites de um texto como este, buscaremos analisar a participação e a apropriação das aulas de EF pelos alunos que se encontram na "periferia" da quadra.

\section{Procedimentos metodológicos}

A pesquisa se deu a partir da etnografia, observando os pressupostos de Fonseca (1999), Geertz (1989) e Magnani (2002). Ao longo da pesquisa, coletamos os dados por meio de observações realizadas em aulas de EF de uma turma de $7^{0}$ ano do Ensino Fundamental de uma escola pública, entrevistas com professores e alunos da turma em questão e análise de documentos da escola. As observações, apesar de centradas nas aulas de EF, também contemplaram os momentos de recreio, a entrada 
e a saída de alunos, pois, nesses momentos, poderíamos observar os alunos na dinâmica escolar e não apenas na dinâmica da turma, o que era pertinente ao estudo.

0 trabalho de campo teve a duração de 6 meses (maio a dezembro de 2009). Durante esse período foram observadas 32 aulas de EF, num total de 50 visitas feitas à escola pesquisada. Entretanto, só consideraremos, para fins deste texto, as observações oriundas das aulas de EF.

Dessa forma, propusemo-nos a analisar a participação e a apropriação das aulas de EF, pelos alunos que se encontram na "periferia" da quadra, entendendo que o acesso à dinâmica cultural empregada por eles no contexto da aula de EF muito tem a contribuir para o melhor entendimento da dinâmica cultural que cerca a prática da EF escolar. No entanto, na direção que afirma Fonseca (1999), compreendendo nossas análises como hipóteses a serem "exploradas/discutidas" ao lado de outras, servindo para oferecer uma alternativa e abrindo o leque de interpretações possíveis, mas não para fechar o assunto ou criar novas fórmulas dogmáticas.

Olhar para a "periferia” da quadra traduz o esforço de melhor compreender outras formas de se pensar e fazer a EF.

\section{A escola e os atores da pesquisa}

A pesquisa foi desenvolvida numa escola de Ensino Fundamental da rede municipal de uma capital brasileira ${ }^{1}$ Na época, a escola contava com um espaço físico privilegiado: amplas salas de aula, biblioteca, sala de informática, duas quadras poliesportivas, salas de vídeo e música, espaço reservado à rádio da escola, espaço que abrigava os materiais utilizados nas aulas de EF, cinco banheiros (quatro destinados aos alunos), além das salas de Direção, Coordenação Pedagógica, Secretaria, refeitó-

1. Para que seja preservado o anonimato dos voluntários da pesquisa, não identificaremos o município, uma vez que se trata de uma unidade escolar com características singulares e que seria facilmente reconhecida. Também utilizamos pseudônimos.

2. A opção por uma turma do Ensino Fundamental II deu-se pelo argumento de que as turmas que se encontram nesse nível de ensino, estando há mais tempo na educação escolarizada, poderiam fornecer dados mais consistentes em relação ao objetivo da pesquisa. A não opção pelo Ensino Médio justifica-se pelo entendimento de que fatores como vestibular e trabalho (emprego), comumente presentes ao final da escolarização, poderiam comprometer a investigação. rio e sala dos professores.

Como atores da pesquisa, participaram o professor de EF (João) e, como já dito, os alunos do $7^{0}$ $a^{2} o^{2}$. Dentre os professores de EF da escola, João, na época da pesquisa, era o que estava há mais tempo na instituição, bem como o que acumulava maior experiência profissional. Com 23 anos de formação, tinha 9 anos de experiência na Educação Básica e os outros 14 anos na área esportiva, tendo atuado como técnico e atleta. 
$07^{0}$ ano era uma turma formada por 25 alunos, dos quais 15 meninos e 10 meninas. Segundo o professor João, tratava-se de uma turma inquieta e desafiadora, pois eles não se interessavam por atividades mais diretivas. De acordo com os próprios alunos, a turma conversava demais, era agitada.

As aulas de EF aconteciam 2 vezes por semana, com duração de 50 minutos cada uma. No período de realização da pesquisa, os conteúdos desenvolvidos foram: voleibol e handebol.

\section{As aulas de Educação Física}

As aulas de EF do $7^{0}$ ano da Escola dos Sonhos obedeceram a uma rotina bem delimitada. 0 professor João iniciava as aulas em sala, na qual fazia a chamada dos alunos, dava alguns recados e explicava o que iriam fazer e, posteriormente, dirigia-se para a quadra com eles para realizar o previsto. No caso de aula em sala, o professor, após a chamada e os recados, dava início à explanação do conteúdo e desenvolvia seus argumentos, buscando a participação de todos por meio de inúmeros questionamentos.

Classificamos as aulas do professor João em três categorias:

Aulas diretivas: o professor propunha a atividade e intervinha com os alunos, instigando-os a pensar outras possibilidades para as ações desenvolvidas.

Aulas de práticas livres: o professor João determinava uma tarefa e, ora a distância, ora mais perto, observava o andamento da atividade. Sua intervenção limitava-se a algumas dicas técnicas em relação aos gestos realizados pelos alunos e à garantia da realização da atividade, chamando a atenção de alguns que insistiam em se desvirtuar para o futebol.

Aulas livres: o professor apenas fornecia o material, controlava o tempo, intervinha em situações extremas, como brigas e/ou ofensas, e participava esporadicamente dos jogos desenvolvidos. A atividade exclusiva das aulas livres foi o futebol, sendo a metade do tempo da aula destinado ao jogo dos meninos e a outra metade, ao jogo das meninas. Na espera pela vez de jogar, meninas e meninos ocupavam o tempo de várias formas: assistindo ao jogo da arquibancada, conversando com o professor, praticando futebol nos arredores da quadra, ouvindo música, dançando, ensaiando algumas brincadeiras como pega-pega ou, simplesmente, jogando conversa fora.

Embora o modelo de aula livre do Professor João esteja mais próximo de uma prática de “não aula”, devido à ausência ou à precária diretividade docente - um dos 
pilares de qualquer processo de ensino-aprendizagem -, neste estudo a aula livre será entendida como aula, pois, minimamente, ocorreu no tempo e no espaço institucionalmente destinados à disciplina EF. Assim, corroboramos o entendimento de que a aula, no sentido de Fontana (2001), abordada em Rodrigues Júnior e Silva (2008), é um acontecimento intersubjetivo, permeado por diversos sentidos e inúmeros processos, dentre os quais se situam o encontro e o confronto de conhecimentos na relação entre alunos e professores.

A partir dessa classificação, construída nas/pelas observações em campo, concluímos que as aulas de EF aconteciam de maneira distante do que se espera de um componente curricular, numa perspectiva esportivizada e não diretiva³.

Diante do fato, todos os alunos, em algum momento da aula (uns mais que os outros), se distanciavam da proposta do professor, caracterizando a condição de imersos na "periferia" da quadra.

A partir das observações, percebemos que tal condição se dava ora por desinteresse dos alunos em relação à atividade proposta pelo professor (conteúdo), ora por desinteresse em relação à forma com que ela era desenvolvida (método).

Diante do contexto, propusemo-nos a sistematizar a participação/apropriação dos alunos nas aulas de EF. Assim, chegamos a três modelos interpretativos do envolvimento dos alunos situados na "periferia" da quadra, o que, longe de ser uma sumária classificação, representa uma forma de compreensão das aulas de EF no contexto escolar, a saber: o "pedacinho" (im) praticante, o “pedacinho" ativo e o "pedacinho" flutuante.

O termo "pedacinho" é oriundo de Souza (1998)4, mas, principalmente, uma alu-

3. 0 termo "não diretiva”, aqui utilizado para caracterizar a prática pedagógica do professor João, tem alicerce em Snyders (1978). Para o autor, as pedagogias não diretivas têm como prerrogativa uma parcial ou total ausência do professor no decorrer da prática pedagógica. Ou seja, há certa "abdicação do mestre", para usar um termo do próprio autor, no processo de ensino-aprendizagem. Fato recorrente na docência do Professor João.

4. Ao referir-se à favela de Acari, Souza (1998, p. 55) afirma: “Aonde pensavamos [sic] existir Acari, descobrimos haver quatro localidades: Coroado, Amarelinho, Vila Esperança e Parque Acari. E onde acreditávamos [sic] haver uma localidade, o Coroado por exemplo [sic], vimos que existem vários “pedacinhos””. Essa afirmação encaixa-se no presente texto, devido à mesma percepção que tivemos, a posteriori, de que o universo micro da quadra da escola era constituído por vários "pedacinhos". são à categoria "pedaço", cunhada por Magnani (1984, 2002). Para o autor, o pedaço é uma categoria de análise da dinâmica cultural urbana, o qual compreende o entendimento de um espaço - ou segmento dele -, que, “[...] assim demarcado torna-se ponto de referência para distinguir determinado grupo de frequentadores como pertencentes a uma rede de relações [...]" (Magnani, 2002, p. 21 e p. 20, grifos nossos). Assim, a noção de pedaço “[...] supõe uma referência espacial, a presença regular de seus membros e um código de reconhecimento e comunicação entre eles”. 
Desse modo, se, para Magnani (2002), ser do pedaço, no plano da cultura urbana, significa exercer uma particular sociabilidade e apropriação do espaço urbano, no contexto de uma aula de EF, numa escola, pode significar relacionar-se com certos colegas - e não com todos - de certo jeito, bem como apropriar-se da aula, a partir de algumas fronteiras, estas moldadas por uma rede de relações.

\section{0s "pedacinhos"}

A concretização dessa conformação (os "pedacinhos") deu-se pela rigorosa observação das regularidades presentes nas relações entre os alunos do $7^{\underline{0}}$ ano nas aulas de EF, nos recreios e nos momentos de entrada e saída da escola.

Dessa forma, o que segue é o mergulho nos "pedacinhos", a partir dos três pressupostos elucidados em Magnani (2002) e citados acima:

- códigos de pertencimento;

- referência espacial;

- presença regular de seus membros.

\section{0 "pedacinho" (im)praticante}

A primeira consideração a ser feita em relação a esse "pedacinho" é que se trata do único exclusivamente feminino, o que não nos causou tanta surpresa, na medida em que a tradição da prática esportiva moderna, frequentemente associada à masculinidade ${ }^{5}$, sempre limitou o acesso às mulheres. Sousa e Altmann (1999, p. 59) corroboram essa perspectiva, afirmando que essa imagem do esporte afasta as mulheres de sua prática.

Se freqüentarmos [sic] quadras esportivas em algum parque num final de semana, provavelmente encontraremos um número significativamente maior de homens do que de mulheres jogando. Também nas escolas as quadras esportivas são normalmente ocupadas por meninos durante o recreio e horários livres, o que, até certo ponto, demonstra que eles dominam esse universo.

O “pedacinho" (im)praticante esteve povoado por três meninas: Antônia, Maria e Isabela. Apesar de serem consideradas as alunas mais estudiosas do $7^{0}$ ano, esse mesmo empenho Fernandes (2008) e Saraiva (2005). 
não era percebido nas aulas de EF. Nestas, Antônia, Maria e Isabela encontravam-se constantemente avessas à possibilidade de se envolver com as práticas corporais. $\mathrm{Na}$ $2^{\underline{a}}$ e na $31^{\underline{a}}$ aulas observadas - respectivamente, uma prática livre dos fundamentos de voleibol e um jogo de queimada -, as alunas participaram parcialmente das atividades. Entretanto, tal participação durou apenas alguns minutos, e logo foi possível notá-las encostadas nos alambrados ou sentadas nas arquibancadas. Exceto nessas duas ocasiões, em quase seis meses de observação, as três alunas não se envolveram com as aulas de EF.

Questionadas sobre o porquê de não fazer a aula, os argumentos expressos em frases “Não gosto!”, “Não levo jeito!”, “A aula é sempre a mesma coisa, muito repetitiva!" foram comuns.

Assim, distante do enredo das práticas corporais, "as três" desfrutavam, nas aulas de EF, de uma sociabilidade que se traduzia em fazer qualquer coisa, menos envolver-se com a turma para qualquer jogo ou atividade corporal. Dessa forma, adotavam, como espaço físico privilegiado de convivência nas aulas de EF, a arquibancada e os arredores da quadra, que compunham a referência espacial do "pedacinho" (im) praticante.

Dentre as práticas de "quaisquer coisas", além das conversas indecifráveis, dos risos intermináveis e de algumas cantorias, foi observado que elas se empenhavam em alguns desenhos e pinturas, bem como, em raras oportunidades, arriscavam alguns passos de dança.

A aula de EF servia como um tempo menos rígido, no qual podiam exercer a liberdade dada pelo professor, para opor-se às práticas corporais esportivizadas. Dessa forma, o tempo e o espaço da aula de EF praticamente traduziram um momento descontraído, destinado a nada ou ao descanso da rotina rígida imposta pelas outras disciplinas.

Assim, estiveram limitadas no horizonte do entendimento de que aquele tipo de prática, calcada no esporte, tendo como conteúdo privilegiado o futebol, não era para elas. Ou seja, continuaram reféns de um conhecimento limitado, no que se refere às práticas corporais, que, deixadas de lado nas aulas de EF, cederam espaço para toda e qualquer influência estereotipada advinda de outras instituições, como, por exemplo, a mídia, que valoriza a competição e o rendimento esportivo, em detrimento das outras manifestações corporais.

Dessa forma, podemos afirmar que a apropriação das aulas de EF pelas alunas do 
“pedacinho" (im)praticante, dada pelo não fazer e pela oposição ao modelo de aula que se instaurou na EF, ocorreu na esteira do extremo reducionismo e, invariavelmente, levou-as à atitude cômoda de não participar da aula. Uma espécie de círculo vicioso, também notado na conformação dos outros pedacinhos, entretanto, a partir de caminhos diferentes.

\section{0 "pedacinho" ativo}

Futebol. Eis a prática privilegiada que, de certa forma, deu vida ao "pedacinho" ativo. Tratava-se de um "pedacinho" que congregava a maior parte da turma, formando um bloco consistente que dava direção às aulas, já que existia a prerrogativa docente de maior liberdade dos alunos nas aulas de EF. Eram membros regulares desse “pedacinho" os seguintes alunos: Diogo, Marcos, Ismael, Caio, Elton, Eduardo, Pedro, Fábio, Fabrício, José, Vitor, Mateus, Paulo, Ana, Clara e Joana.

Em todas as aulas de EF observadas, esse grupo de alunos sempre esteve disposto a qualquer prática corporal proposta pelo professor, entretanto, com extremos apelos ao futebol, fato que ocorreu em quase todas as aulas.

Além da disposição às práticas corporais desenvolvidas nas aulas de EF, o código de pertencimento do "pedacinho" ativo era predominantemente representado pelo mundo do futebol: jogar futebol, conversar sobre futebol, comentar o Campeonato Brasileiro de Futebol de 2009, etc.

A preferência por tal prática não foi de difícil entendimento: sendo a EF encarada como um tempo e um espaço menos rígidos do processo educacional, aliado a uma prática pedagógica, predominantemente esportiva e não diretiva, o tempo-espaço da aula de EF cedeu lugar às influências diversas que os alunos traziam consigo. No caso da aula de EF, o futebol tomava conta. Para Daolio (2003, p. 156), “[...] o futebol faz parte da sociedade brasileira de uma maneira mais efetiva talvez do que podemos supor à primeira vista. A sociedade brasileira - não é exagero dizer - está impregnada de futebol [...]".

Assim, o “pedacinho" ativo colocava-se em prol do futebol em qualquer aula, ensaiando dribles, chutando qualquer objeto em direção ao gol ou criando formas de adaptação de outros esportes ao futebol ${ }^{6}$.

Dessa forma, qualquer espaço físico que per-

6. Em certa aula, o professor João propôs que os alunos praticassem a manchete do voleibol em grupos de três ou quatro pessoas. Não demorou muito para que um grupo de meninos modificasse a prática: colocaram um colega de goleiro e buscavam fazer o gol de manchete. Sem mencionar que, em todos os jogos de voleibol desenvolvidos nas aulas, sempre havia jogadas com os pés. Quando o professor João buscava recriminar tal prática, sempre ouvia a mesma resposta: "Professor, mas agora pode com o pé...". 
mitisse, minimamente, o desenvolvimento do futebol ou de qualquer outra atividade corporal era usufruído pelo "pedacinho" ativo. Mas, sem dúvida, a referência espacial de destaque constituía-se no espaço de jogo da quadra da escola.

Entretanto, apesar de o código de pertencimento desse "pedacinho" estar ligado ao futebol e/ou qualquer outra prática corporal, a forma como se aproximavam dessas práticas se dava em escalas distintas. A primeira escala de distinção opunha meninos e meninas, permitindo o seguinte desdobramento: o "pedacinho" ativo masculino (composto por 13 integrantes) e o "pedacinho" ativo feminino (composto por 3 integrantes).

No desenvolvimento das aulas de voleibol e handebol, os meninos do "pedacinho" ativo buscavam monopolizar a prática, ou seja, queriam escolher os times, jogar mais tempo que os outros, bem como, se possível, interagir somente com outros meninos, principalmente nas práticas livres. Entretanto, toda essa atividade nada mais era que um reflexo de uma dinâmica já desenvolvida no futebol.

Os meninos do "pedacinho" ativo, em todas as oportunidades em que desenvolveram o futebol, o fizeram a partir de um conjunto de padrões:

- o drible era exacerbado, não havendo, praticamente, troca de passes;

- o contato corporal era feito a partir de um padrão de disputa pela bola com forte apelo físico;

- havia a procura pelo equilíbrio dos times; assim, a escolha obedecia a um consenso de que jogadores de habilidade semelhante não podiam jogar no mesmo time, a não ser que do outro lado houvesse equivalência em número e qualidade; e

- a arbitragem era compartilhada por todos, sendo discutida coletivamente, a todo momento, durante as partidas.

Apesar de compartilharem a mesma referência espacial, as meninas do "pedacinho" ativo eram extremamente críticas ao fato de terem praticamente menos oportunidades nos jogos de voleibol e handebol. Passavam quase toda a aula chamando a atenção do professor para isso. Entretanto, como a postura não diretiva norteava as ações do professor, a desigualdade de oportunidades imperava. Mas, apesar disso, as meninas do "pedacinho" ativo não abriam mão da participação - pelo contrário, resistiam, criticavam, respondiam aos meninos e, nas aulas livres, fiscalizavam o relógio do professor para certificar-se de que o tempo seria cumprido. Assim, Ana, Clara e Joana (membros do "pedacinho" ativo) sempre estavam próximas aos meninos para assegurar que nenhuma desigualdade haveria. Queriam os mesmos direitos. Fato 
esse corroborado em Sousa e Altmann (1999), quando afirmam que há um movimento das meninas na direção da ruptura de hierarquias de gênero no esporte?

O futebol desenvolvido por elas nas aulas livres de EF só era possível devido às ações das integrantes do "pedacinho" ativo. Pelo baixo quórum - as três meninas mais outras colegas do "pedacinho" flutuante (máximo de três) -, elas sempre chamavam meninos para completar os times, porém, na função de goleiro, que, se desempenhada pelos meninos no jogo das meninas, estava limitada ao desenvolvimento de ações apenas dentro da área. Ou seja, eles não podiam participar do jogo com os pés, sendo permitida a utilização dessa parte do corpo somente em defesas ou reposição de bolas. Também não podiam tentar fazer gol com o chute direto para a meta adversária: havia obrigatoriedade de tocar para uma componente de seu time. Assim, mesmo que houvesse compreensão de certa superioridade masculina no futebol por parte dos meninos que participavam, haja vista a imposição de algumas restrições, para as meninas essa conformação configurava a única possibilidade de jogarem, já que ficaria muito difícil jogar com apenas três meninas de cada lado.

Dessa forma, concordando com Altmann (1998, p. 44), podemos destacar que as meninas não são vítimas de uma exclusão masculina. "Vitimá-las significaria coisificá-las, 'aprisioná-las pelo poder', desconsiderando suas possibilidades de resistência e também de exercício de dominação". Resistência que pode ser percebida no "pedacinho" ativo feminino.

Assim, pudemos chegar a uma possível consideração sobre o "pedacinho" ativo: apesar de os alunos se disporem para a prática corporal, o que é positivo, o "pedacinho" ativo também é refém de um horizonte de conhecimento limitado, no que se refere às práticas corporais. Isso porque, mesmo fazendo uso de estratégias diferenciadas nas suas práticas, os alunos estavam imersos em desigualdades de oportunidades, mediadas por uma hierarquia de critérios, os quais determinavam quem jogava mais e quem jogava menos. E também compartilhavam de um horizonte esportivo limitado pela prática do futebol.

Outro fato refere-se à compreensão da aula de EF como espaço único e exclusivo destinado ao futebol, reforçando a legitimidade da disciplina como tempo/espaço menos rígido da escola. Além disso, as constantes intrigas de gênero acabaram por denotar, independentemente do valor positivo das resistências das meninas, que a aula de EF deve ser distinta para meninos e meninas. Do lado masculino, a reclamação de que as

7. Ver mais em Altmann (1998). 
meninas não jogavam direito; do lado feminino, a reclamação de que os meninos não tocavam a bola para elas.

Portanto, podemos afirmar que a apropriação das aulas de EF pelo "pedacinho" ativo, dada pela prática estereotipada do futebol, também ocorreu, assim como no "pedacinho" (im)praticante, no limite do reducionismo. E levou os alunos à comodidade de vivenciar sua maior liberdade no conformismo, fruto do círculo vicioso permitido pela existência da "periferia" da quadra.

\section{0 "pedacinho" flutuante}

Antes de tecermos maiores considerações em relação a esse "pedacinho", é preciso afirmar que ele se encontrava na fronteira entre o "pedacinho" (im) praticante e o "pedacinho" ativo (Ilustração 1). Entretanto, a ideia de fronteira aqui utilizada não se refere a uma demarcação rígida, mas indica uma zona intermediária, em estreita ligação com os outros dois "pedacinhos", que não são opostos, pois apenas representam formas diferenciadas de aproximação das práticas corporais.

\section{Ilustração 1 - Esquema gráfico do "pedacinho" flutuante.}

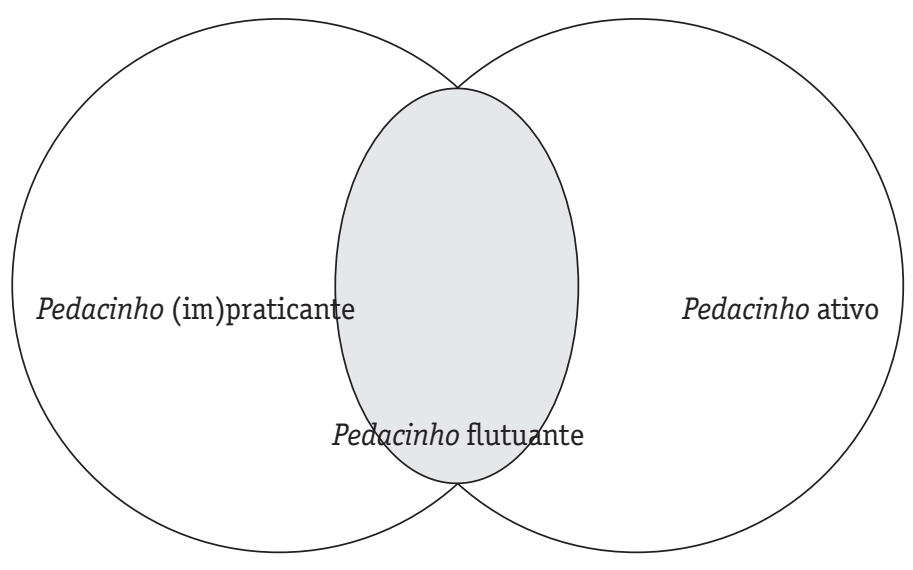

Fonte: os próprios autores.

Apesar de a ilustração remeter à hipótese matemática da intersecção de conjuntos, o destaque dado ao "pedacinho" flutuante não significa que nele estejam contidos elementos existentes, simultaneamente, no "pedacinho" (im)praticante e no "pedacinho" ativo. Mas indica que, no interior do "pedacinho" flutuante, podem 
coexistir aspectos distintos, presentes nos códigos de pertencimento dos dois outros “pedacinhos", bem como a ausência de uma referência espacial nítida, estando a utilização do espaço físico da quadra privada de qualquer predeterminação por parte de seus membros. Dessa maneira, o "pedacinho" flutuante congregou uma forma de sociabilidade que tanto permitiu o envolver-se com as práticas corporais nas aulas de EF, estreitando relações com o "pedacinho" ativo, quanto o não fazer, compartilhando, em parte, do horizonte do "pedacinho" (im)praticante.

Aqui, nitidamente, os alunos "incorporavam" somente parte das ideias de ambos os "pedacinhos", não estando sujeitos à rigidez do fazer tudo e do não fazer nada, operando, assim, entre reflexões e interesses que ora penderam para um lado, ora para outro. Entretanto, tal condição não permitiu o rótulo de que os alunos pertencentes a esse "pedacinho" se encontravam "em cima do muro". Pelo contrário, havia posições bem demarcadas e pontuais, que possibilitavam aos outros "pedacinhos" a visualização de que, embora na arquibancada ou no espaço de jogo ou mesmo conversando e rindo ou jogando futebol, eles possuíam leituras distintas.

Eram integrantes do "pedacinho" flutuante os seguintes alunos: Adriana, Marcela, Teresa, Adriano e Marcelo. Apesar de constituírem um grupo pequeno, compartiIhando as mesmas regularidades em relação às práticas corporais, as meninas e os meninos desse "pedacinho" praticamente não interagiam entre si, pois existia uma barreira de gênero mais concreta do que a elucidada no "pedacinho" ativo, externada ao restante da turma. Diante disso, podem-se notar diferentes formas de sociabilidade no interior do "pedacinho" flutuante, em interação direta com os outros "pedacinhos", como delineamos abaixo.

“Elas querem saber mais de namorico, conversar, essas coisas". Assim Clara definiu o interesse de Adriana e Marcela durante as aulas de EF. Fazendo isso, além de pontuar certa crítica, pois para Clara as colegas deveriam estar interessadas nas aulas, havia a intenção, também, de diferenciar-se. Ou seja, jogam com a gente ("pedacinho" ativo), mas não compartilham das mesmas ideias.

Entretanto, para Adriana e Marcela, o entendimento era outro: achavam-se livres para usufruir do tempo e do espaço das aulas de EF para conversar, rir, dançar, não fazer nada ou não se empenharem nas atividades propostas pelo professor João. Por outro lado, também viam como legítimas as reivindicações do "pedacinho" ativo feminino por igualdade entre meninos e meninas nas aulas e tinham sempre participado dos momentos em que o futebol feminino ganhava vez nas aulas livres. Assim, o reca- 
do ao "pedacinho" ativo feminino era nítido: chamem-nos para jogar futebol, mas não nos imponham as mesmas ideias. Assim, o futebol feminino nas aulas livres se desenvolveu a partir do embate entre flutuantes e ativas, vivenciado num clima bem descontraído por parte do "pedacinho" flutuante - no qual o interesse estava mais na diversão - e mais acirrado por parte do "pedacinho" ativo, que buscava dribles, chutes e gols.

Em relação a Adriano e Marcelo, também era nítida a peculiar forma de vivenciar as aulas de EF. No futebol das aulas livres e nas práticas corporais que existiram nas outras aulas de EF na quadra, ao estarem em contato com o "pedacinho" ativo, exerciam uma participação que se distanciava dos principais extremismos dos (im) praticantes e ativos. Assim, quando jogaram voleibol e handebol, demonstraram interesse pela atividade, empenhando-se nas ações coletivas, mas sem compartilhar dos apelos "futebolescos" do "pedacinho" ativo. No futebol das aulas livres, quando participaram, Adriano e Marcelo não se preocupavam muito com o rigor das escolhas dos times, com a hierarquia estabelecida, muito menos com a arbitragem discutida. Notávamos que os dois procuravam desenvolver a prática mais no limite da contribuição para com as ações ofensivas e defensivas de seus times do que na exacerbação do drible e do individualismo. Quando sofriam alguma falta, raramente se pronunciavam: ora aguardavam os argumentos de seus colegas de equipe, ora prosseguiam no jogo. Tal fato poderia ser entendido como certa passividade; entretanto, mais representava diferenciação do que voz passiva.

Quando não jogavam ou não se envolviam nas práticas corporais possibilitadas nas aulas de EF, Adriano e Marcelo podiam ser vistos na arquibancada, entretidos com algumas coisas, das quais a mais frequente era a contemplação da própria aula. Assim, mesmo não se dispondo às práticas corporais, a atenção dos dois esteve predominantemente nelas.

Assim foi que o "pedacinho" flutuante vivenciou sua sociabilidade na amplitude das referências espaciais dos outros "pedacinhos", mas guiado por um pressuposto intermediário que não compartilhava exatamente dos mesmos códigos de pertencimento presentes nos demais. Esteve guiado por um código de pertencimento embasado pela liberdade de optar ou não pelas práticas corporais, cuidando para que tal perspectiva não os distanciasse muito de seus colegas de turma. Assim, utilizavam-se da maior liberdade nas aulas de EF para flutuar, de acordo com seu interesse, entre a participação nas práticas corporais e os namoricos, as conversas ou, simplesmente, a observação do que se passava. Porém, sem endossar, na íntegra, as outras perspectivas. 
Contudo, apesar da diferenciação, acabaram por vivenciar os mesmos reducionismos presentes nos outros "pedacinhos". Dessa forma, a apropriação das aulas de EF pelos integrantes do "pedacinho" flutuante também se deu no horizonte de conhecimento limitado, no que se refere às práticas corporais, como ocorria nos outros "pedacinhos".

\section{Considerações finais}

Compreender a aula de EF como constituída por atores sociais pertencentes a diferentes redes de relações, a diferentes “pedacinhos”, possibilita o entendimento de que aquilo que se pensa como exclusão pode ser lido na chave das diferentes formas de participação e apropriação da aula de EF.

Assim, se a "periferia" da quadra é o pedaço no qual se vivenciam outras possibilidades de sociabilidade constantemente limitadas ou negadas pela escola, foi nos "pedacinhos" que essas experiências ganharam vida e delinearam inúmeras tramas da complexa rede de sociabilidade instaurada nas aulas de EF - observadas neste estudo. Dessa forma, foi possível compreender que os alunos, nas aulas de EF, imersos na "periferia" da quadra, vivenciaram sua sociabilidade, na perspectiva de um tempo e um espaço de livre convivência com o Outro, limitada pela rigidez imposta do cotidiano escolar.

Entretanto, para além de inúmeras possibilidades de convivência com esse Outro, a sociabilidade vivenciada no interior dos "pedacinhos" e entre estes foi marcada por uma trama norteada pelo conformismo, que, consequentemente, foi permeada por estereótipos, preconceitos e desigualdades de oportunidades. Dessa forma, o fenômeno da "periferia" da quadra alerta para a necessidade de repensar o tipo de prática pedagógica descrita neste estudo.

Diante do exposto, entendemos que as aulas devem ser compartilhadas por todos, independentemente da diversidade dos olhares dos discentes sobre elas. Faz-se necessário trabalhar na perspectiva de fazer com que os alunos aprendam algo com a disciplina, com a escola, com seus colegas e com seu professor. Para isso, tal aprendizagem não pode se dar de forma limitada, conforme observado neste estudo.

Se fizéssemos o exercício de visualizar outros componentes curriculares, seria impensável configuração semelhante. Por que, então, na EF tal conformação é permitida? Por que na EF escolar tal conformação é comum, haja vista que outros estudos na área têm evidenciado tais fatos? Em Oliveira e Daolio (2010), que buscaram com- 
preender como as diferenças são significadas e representadas pelos alunos nas aulas de EF; em Souza (2008), que estudou a representação da EF por alunos do ensino médio; em Fernandes (2008), que estudou os sentidos de gênero produzidos por alunos nos dois primeiros anos iniciais do Ensino Fundamental em suas aulas de EF; e em Matsumoto (2009), que estudou o ensino-aprendizado do gesto em suas aulas de EF desenvolvidas na primeira fase do Ensino Fundamental, os mesmos pressupostos evidenciados neste estudo foram percebidos.

Portanto, acreditamos que seja necessária uma prática pedagógica diversa, em termos de:

- Conhecimentos: abarcando todos os conhecimentos da cultura de movimento (jogos, ginástica, lutas, dança, esporte, etc.).

- Compartilhamento amplo: entendemos a importância da existência de uma rede de sociabilidade que se estenda pelas aulas de EF. Porém, não reduzida a grupos e/ ou "pedacinhos", que se propõem a dialogar restritamente com o Outro, mas estimulada na direção de outros "nós", outras amarrações e outras conformações, que apresentem novas perspectivas: mais abertas e menos desiguais, entendedoras da diferença como fator comum a todos os seres humanos, e não um "mais do mesmo".

- Estratégias metodológicas: possibilitar ao aluno não somente propor atividades, mas também vivenciar outras proposições, inclusive as do professor.

Por que não uma aula de ensino de determinada modalidade de luta? Por que não uma aula de ensino do salto em distância? O fazer instrumental não é uma dimensão proibida ou de menor liberdade numa aula de EF. Pelo contrário, pode ser fomentadora de outras leituras e aprendizados corporais. Kunz (1994) já propunha o saber fazer como uma dimensão a ser desenvolvida nas aulas de EF.

Assim, acreditamos que não é desejável que o professor limite sua prática pedagógica a proposições mínimas ou abdique de compartilhar conhecimento de forma mais efusiva, na premissa de que seja dada mais liberdade ao aluno. Advogar maior liberdade aos alunos nas aulas não se restringe a deixá-los livres para desempenhar o que desejam, pelo contrário: “As iniciativas tomadas pelo professor tornam-se condições da própria liberdade da criança [educando]” (Snyders, 1978, p. 255).

Por fim, na mesma esteira de Freire (1997), entendemos que a educação deve fazer com que os alunos ampliem seus desejos e/ou os conheça melhor; ou seja, saber melhor o que já sabem e passar a saber o que não sabem. Para isso, além de outros estudos, outras práticas pedagógicas são necessárias. 


\section{Referências bibliográficas}

ALTMANN, Helena. Rompendo fronteiras de gênero: Marias (e) homens na educação física. 1998. 111f. Dissertação (Mestrado em Educação) - Faculdade de Educação, Universidade Federal de Minas Gerais, Belo Horizonte.

BRACHT, Valter et al. Pesquisa em ação: educação física na escola. Ijuí: Unijuí, 2003, 128p.

CASTELLANI FILHO, Lino. Educação Física no Brasil: a história que não se conta. Campinas: Papirus, 1988. 176p.

DAOLIO, Jocimar. Cultura, educação física e futebol. 2. ed. Campinas: Unicamp, 2003. $152 \mathrm{p}$.

DEVIDE, Fabiano. P. Gênero e mulheres no esporte: história das mulheres nos Jogos Olímpicos Modernos. ljuí: Unijuí, 2005. 144p.

FERNANDES, Simone C. Os sentidos de gênero nas aulas de Educação Física. 2008. 116f. Dissertação (Mestrado em Educação Física) - Faculdade de Educação Física, Universidade Estadual de Campinas, Campinas.

FONSECA, Cláudia. Quando cada caso NÃO é um caso: pesquisa etnográfica e educação. Revista Brasileira de Educação, Rio de Janeiro, n. 10, p. 58-78, abr. 1999.

FONTANA, Roseli A. C. Sobre a aula: uma leitura pelo avesso. Presença Pedagógica, Belo Horizonte, v. 7, n. 39, p. 31-37, jun. 2001.

FREIRE, Paulo. Ética e educação. Palestra proferida na Escola Americana em São Paulo. 1997. Gravação em vídeo.

GEERTZ, Clifford. A interpretação das culturas. Rio de Janeiro: LTC, 1989. 213p.

KUNZ, Elenor. Transformação didático-pedagógica do esporte. ljuí: Unijuí, 1994. 152p.

MAGNANI, José G. C. De perto e de dentro: notas para uma antropologia urbana. Revista Brasileira de Ciências Sociais, São Paulo, v. 17, n. 49, p. 11-29, jun. 2002.

MAGNANI, José G. C. Festa no pedaço: cultura popular e lazer na cidade. São Paulo: Brasiliense, 1984. 198p.

MATSUMOTO, Marina. H. O ensino-aprendizado do gesto na aula de Educação Física. 2009. 211f. Dissertação (Mestrado em Educação) - Faculdade de Educação, Universidade Estadual de Campinas, Campinas.

OLIVEIRA, Rogério C.; DAOLIO, Jocimar. Educação física, escola e cultura: da diferença como desigualdade à alteridade como possibilidade. Movimento, Porto Alegre, v. 16, n. 1, p.149-167, jan./mar. 2010.

RODRIGUES JÚNIOR, José C.; SILVA, Cinthia L. A significação nas aulas de Educação 
Física: encontro e confronto dos diferentes "subúrbios" de conhecimento. ProPosições, Campinas, v. 19, n. 1, p. 159-172, abr. 2008.

SARAIVA, Maria do C. Co-educação física e esportes: quando a diferença é mito. 2. ed. ljuí: Unijuí, 2005, 196p.

SNYDERS, George. Para onde vão as pedagogias não-directivas? 2. ed. Lisboa: Moraes Editores, 1978. 365p.

SOUSA, Eustáquia S.; ALTMANN, Helena. Meninos e meninas: expectativas corporais e implicações na Educação Física escolar. Caderno CEDES, Campinas, v. 19, n. 48, p.52-68, ago. 1999.

SOUZA, Adalberto S. Educação física no ensino médio: representações dos alunos. 2008. 148f. Tese (Doutorado em Educação Física) - Faculdade de Educação Física, Universidade Estadual de Campinas, Campinas.

SOUZA, Marcos A. P. As cores de Acari. 1998. 285p. Tese (Doutorado em Antropologia) - Faculdade de Filosofia, Letras e Ciências Humanas, Universidade de São Paulo, São Paulo.

Submetido à avaliação em 21 de novembro de 2012. Aprovado para publicação em 20 de junho de 2013. 